\title{
The effect of a soy-yoghurt-honey product on excess weight and related health risk factors - A review
}

\author{
Sadaf Koohkan', David H McCarthy², Aloys Berg ${ }^{3 *}$ \\ ${ }^{1}$ Clinikum rechts der Isar, Technical University of Munich, Chair and Polyclinic for Prevention, Rehabilitation and Sports Medicine, Germany. \\ ${ }^{2}$ Department of Health and Human Sciences, London Metropolitan University, London, UK \\ ${ }^{3}$ Faculty of Medicine, University of Freiburg, Germany
}

Received: February 06,2017; Accepted: February 28,2017; Published: March 15, 2017

*Corresponding author: Prof. Dr. Med Aloys Berg, Medizinische Fakultät der Universität Freiburg. Email: aloys.berg@klinikum.uni-freiburg.de

\begin{abstract}
There is an agreement that long-term Therapeutic Lifestyle Changes (TLC) such as dietary behavior reformations and increasing daily physical activity, are the cornerstones in the prevention and management of obesity and its related health risk factors. Furthermore, the use of meal replacement diet has been accepted as an effective therapeutic strategy for a successful weight loss, particularly in the beginning of an intervention. The following review will specially focus on the efficiency of a clinically approved meal replacement product which is commercially available as a Soy-Yoghurt-Honey Formula (SYHF) which can be used to prevent, treat or manage overweight, obesity and its related health risks. The mentioned positive effects come not only by formula's low glycemic index as well as low caloric characteristics, but by its biologically active components such as soy isoflavones and soy and milk biological active peptides as well as antioxidants, enzymes and oligofructose from honey. Indeed, the consumption of soy protein can be a nutritional strategy to oxidize more fat, and there is experimental evidence that soy protein influences cellular energy metabolism by molecular mechanisms improving insulin sensitivity and plasma lipid levels. Due to these mechanisms, acute and permanent effects could be demonstrated for SYHF in experimental and controlled clinical studies which are directed to successful weight reduction as well as significant benefits on metabolic dysfunction. Possible benefits of weight loss on quality of life and cognitive function after SYHF intake are other aspects of meal replacement with SYHF which were discussed. - The facts given, approve the statement that SYHF present a successful as well as safe approach to weight loss and to improve the metabolic milieu within a sustained time period, independent of sex, age and diagnosed symptoms of the metabolic syndrome.
\end{abstract}

\section{Introduction}

\section{Goal-Setting: Realisticweightloss}

Weight reduction programs are a part of many standard obesity treatment and prevention guidelines such as the German Obesity Society guidelines, concerning success and quality [85]. The aim of these weight loss strategies is not weight loss alone but also an improvement of cardiovascular and metabolic risk factors, following a healthy lifestyle (physical activity and diet) and raising the quality of life. To achieve this goal, supervised programs can be applied over a period of at least 6 months delivered by an interdisciplinary team of physicians, psychologists and group behavior consultants and nutritionists. This approach produces healthy modifications in diet and exercise for an individual's every day practice [10].

Even if such a program isinsufficient to prove the long-term success, the significant findings in obese adults confirms that using modified lifestyle interventions are at least comparable with the results of pharmacological interventions after 12months [66]. Nevertheless, it is discouraging knowing the level of success in weight loss programs while only a very small number of obese patients can be motivated to participate in a lifestyle intervention program [25].

There is agreement that long-term therapeutic lifestyle changes (TLC) such as dietary behavior reformations and increasing daily physical activity, are the cornerstones in the prevention and management of obesity and its related health risk factors and are often combined with cognitive behavior modification techniques $[10,85]$. Furthermore, the useof meal replacements has been accepted as an effective therapeutic strategy for weight loss, particularly in the beginning of an intervention $[4,5,26,83,85]$.

Dietary approaches can achieve as much weight loss in obese outpatients as has been reported for the most successful drug treatments, but compliance with the prescribed dietcan be poor unless the dietary recommendations are simple to follow [73]. Moreover, weight loss interventions utilizing a meal replacement together with dietary counselling and increased physical activity have led to substantial and significant favorable reductions in anthropometric measurements and metabolic risk factors while preserving skeletal muscle mass $[7,8]$. The following review will specially focus on the efficiency of a clinically proven meal replacement product which is commercially available as a soy-yoghurt-honey formula (SYHF; Almased $囚$ ) against overweight, obesity and its related health risks. 


\section{Bioactive ingredients of SYHF and their molecular basis for clinical effects}

The soy-yoghurt-honey formula (SYHF) which is described in this review with special focus to its effectiveness on weight control and metabolic regulation consists of a combination of soy Protein isolate, yogurt and natural honey; it is clinically tested [26] and is commercially available (Almased®). The product is approved as a food supplement (50 g powder dispersed in $200 \mathrm{ml}$ water) as well as a suitable meal replacement product $(1 \mathrm{~g}$ per kg 'normal' body weight determined from the Broca Index). Furthermore, this formula is a part of "The Almased Concept against Overweight and Obesity and Related Health Risk (ACOORH)" and the basis of a multicenter randomized clinical trial to confirm the effects of SYHF on body composition and comorbidities in overweight patients $[16,17]$. The protein content of this product is 53.3 $\%$ (83 \% soy-protein-isolate, and $17 \%$ milk protein); the product is characterized by a very low glycemic index (GI = 27 ), a very low glycemic load (GL of one consumption unit = 4.1), a low energy content (354 kcal $/ 100 \mathrm{~g}$ dried powder) and biologically available components such as soy isoflavones and biological active peptides (BAP's) from soy and milk as well as antioxidants, enzymes and oligofructose from honey [10]. These bioactive ingredients and the molecular basis for their clinical effects will be presented and discussed in the following chapter (Fig.1).

In contrast to typical east Asian diets, soy still plays a relatively minor dietary role in the usual western food consumption despite it providing an excellent source of high biological value protein and a variety of bioactive compounds. Within these, isoflavones have attracted increased attention because of their health-promoting effects which have been primarily focused on cardiovascular, bone and menopausal health.Genistein and daidzein are the main compounds within the isoflavone class of phytoestrogens (Messina, 1999).

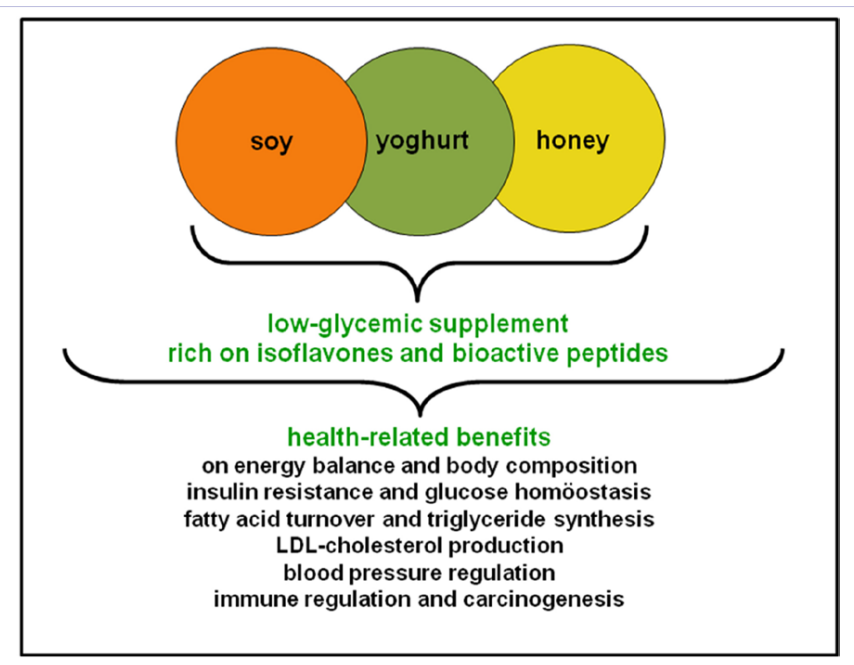

Figure 1: Compounds and ingredients of the SYHF product (Al-

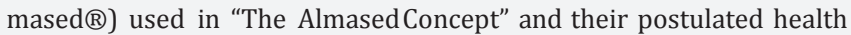
benefits. [14]
As heterocyclic phenols structurally analogous to human estrogens, they bind to estrogen receptors alpha and beta and stimulate transcriptional activities $[22,70]$. Based on their molecular activities, soy isoflavones $\mathrm{m}$ a y also have favorable effects on fatty acid metabolism and insulin sensitivity [78]. In addition, conglycinin, soya saponins, and soya phospholipids have also been discussed in relation to obesity. Several nutrition intervention studies in animals and humans have indicated that consumption of soy protein reduces body weight and fat mass, in addition to lowering plasma cholesterol and triglycerides, therefore potentially playing a significant role in the prevention of obesity [76].

To achieve an increased, but safe isoflavone (ISF) intake, the clinically tested soy-yoghurt- honey formula has shown a sufficientamount of biologically available isoflavonoids within around $1.5 \mathrm{mg}$ per g SYHF powder. Given a typical serving of $50 \mathrm{~g}$ of the product per portion, the intake of available isoflavonoids could be calculated as $75 \mathrm{mg} /$ portion; this intake may be sufficient to produce biologically significant increases in blood isoflavone levels [18] which was controlled by measuring the serum isoflavone concentrations (daidzein, genistein, glycitein, equol, and o-DMA) by LCMS analyses. In regard to these phytoestrogens, the European Food Safety Authority, Panel on Food Additives and Nutrient Sources (EFSA ANS) was very recently asked to provide a scientific opinion on the possible association between isoflavones intake from food supplements and harmful effects on mammary gland, uterus and thyroid tissues in per- and post-menopausal women. The Panel stated [32] that food supplements typically provide a daily dose of isoflavones in the range of 35-150 mg/day. A systematic review found no association between isoflavone intake from food supplements and adverse effects on the three target organs. Considering the discussions around isoflavone related risk of breast cancer, the human data reviewed by the Panel did not support the hypothesis of an increased risk of breast cancer from observational studies, neither by an effect on mammographic density nor on proliferation marker Ki67 expression in interventional studies. No effect was found on endometrial thickness and histopathological changes in the uterus up to 30 months of supplementation with 150 $\mathrm{mg} /$ day of soy isoflavones. Thyroid hormones levels were also unchanged following intake of isoflavones from food supplements. Nevertheless, the Panel concluded that it was not possible to derive a single health-based guidance value for the isoflavone preparations, and currently there are no health claims made on isoflavones in foods registered in the EU Register of nutrition and health (http://ec.europa.eu/ nuhclaims/).

The results of a recently performed study on postmenopausal females [50] showed that a daily intake of between 25 to 125 grams of SYHF, significantly increased the blood levels of isoflavones without any changes in their thyroid as well as sex hormone levels. It may be of interest that there was no linear increasein blood ISF levels in relation to dietary ISF intake and that a plateau in ISF blood levels, 
particularly in genistein and daidzein, was reached at an ISF intake of around 100 grams of Almased $\AA$ per day. This phenomenon may be important for the recommendation of a health-related ISF intake by soy products. At this level of ISF intake from soy food, modifications in metabolic and mental functions can accrue which may be responsible for health-related benefits [82]. When the results of our study [50] was interpreted due to the possible side effects, it can be also assumed that the SYHF intake had no specific influence, particularly negative side effects on thyroid function as well as sex hormones level in postmenopausal women. Moreover, the ISF and also SYHF effects on weight regulation (discussed above) are not induced by a hyperthyroid status.

Indeed, the intake of soy protein may be a nutritional strategy to oxidize more fat $[12,45]$ and there is experimental evidence that soy protein influences cellular energy metabolism by molecular mechanisms [57, 63, 74]. In addition, soy protein improves insulin sensitivity and plasma lipid levels by activating peroxisome proliferator activated receptors (PPARs). PPARs are nuclear receptors which regulate metabolic processes, particularly those affecting energy metabolism, by regulating the expression of genes involved in glucose homeostasis, lipid metabolism and fatty acid oxidation. Consumption of isoflavone-rich soy protein improves glucose tolerance, insulin sensitivity and hepatic triglyceride concentrations in rats. In these investigations, isoflavone-rich soy extracts increased the gene expression of PPARs in cell culture, suggesting that the beneficial effects of soy protein on glucose and lipid metabolism may indeed be mediated by PPAR activation [61, 62, 69].

Finally, it was also found [62] that feeding soy protein to rats increased the activity and mRNA levels of several skeletal muscle enzymes involved in fatty acid oxidation, including carnitine palmitoyltransferase (CPT1) activity and betahydroxyacyl-CoA dehydrogenase (HAD), Acyl-CoA oxidase, and medium- chain acyl-CoA dehydrogenase. Moreover, PPAR gamma coactivator PGC1 alpha and PPAR alpha mRNA levels were also found to be elevated, suggesting that soy protein intake stimulates skeletal muscle fatty acid oxidation by activating PPAR pathways, ultimately leading to a reduced accumulation of body fat. Although comparable experimental studies in humans are lacking, there would be no reason to assume that a regular intake of soy would not affect human metabolism in the same manner.

During the last decade there has been increased attention paid to the implications of dietary peptides for modulation of health and disease, particularly in the prevention of metabolic dysregulation and obesity $[75,86]$. In general, peptides are generated in the gut lumen during normal digestion following protein consumption. Most are absorbed as dipeptides and tripeptides through the gut mucosa primarily to supply dietary nitrogen. However, larger peptide fragments are also absorbed and many of these dietary peptides have been shown to have metabolic effects, even at microgram quantities. More than 1500 different bioactive peptides have been reported with various bioactivities and functional significance [71]. The bioactive sequence size can vary from two to twenty amino acids and may reach, (for example the well described soybean peptide Lunasin [54], a chain of 43 amino acids. The bioactivities of these particular peptides, encrypted in proteins, are latent until they are released from their parental proteins. Finally, the feasibility of the biological application of these peptides depends on absorption and the bioavailability of intact forms in target tissues [71].

A large number of bioactive peptides are reported to be derived from milk and soybean; many bioactive peptides are also found in animal and plant sources including egg, fish, oyster, rice, wheat, oat, barley, corn, radish seeds and royal jelly [71]. In the SYHF food product, more than eighty bioactive peptides have been reported with various bioactivities and potentially significant functional benefits for metabolic regulation which may be important for the prevention of obesity $[13,14]$. The SYHF peptides isolated by Liquid Chromatography Mass Spectrometry (LCMS) are known to have potential antihypertensive, anticholesterolemic, antitriglyceridemic, antioxidative and anticancer activities as well as anti obesity or anorectic properties [71] (Fig.2). Another ingredient in SYHF with beneficial properties is honey. Honey was the only available natural sweetener until industrial sugar production began to replace it after 1800 [24]. However, the belief that honey is a food, a drug and an ointment continues today; in the long human tradition, honey has been used not only as a food but also as a medicine [41]. There is a somewhat revival for the use of honey focusing on its health promoting benefits; it has been assumed that honey has a variety of positive nutritional and health effects if consumed at levels of 50 to 80 g per serving [19]. Even though honey is a carbohydrate-rich food, its glycemic index varies across a wide range, depending on the botanical source and its glucose: fructose ratio [28]. Additionally, honey contains various oligosaccharides [6] and small amounts of proteins, enzymes, amino acids, minerals, trace elements, vitamins,

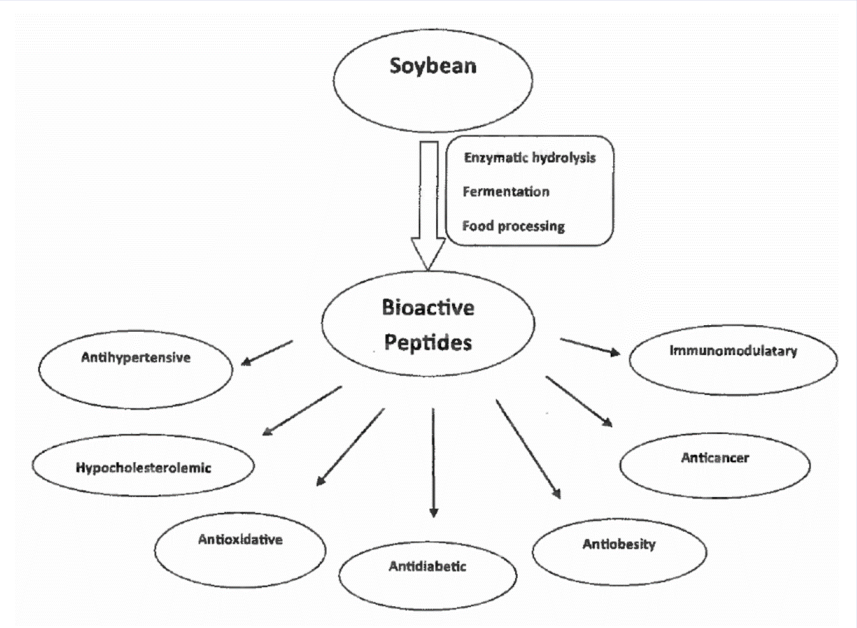

Figure 2: Functional significance of bioactive peptides derived from soybean [71]. 
aromatic compounds and polyphenols [19]. In particular, these oligosaccharides may be responsible for the possible antidiabetic [34] and other health-related benefits of honey $[1,34]$.

In published reviews, [34, 36] the authors provided evidence to support the possible role of gut microflora in the pathogenesis of insulin resistance and glucose dysregulation together with the capability of oligosaccharides to establish the equilibrium of the microbiota ecosystem. If it is possible to regulate the microbiome balance by diet [58, 81], a regular intake of honeyas a replacement of sucrose, could be an option for a beneficial modification of the gut microbiota [80] Honey oligosaccharides, as a replacement for sucrose, seems to influence appetite-regulating hormones as well as energy intake $[35,52]$ which has to be considered as a potentially important benefit of honey for preventing excess weight gain [64]. Since SYHF powder contains $25 \%$ natural honey, a significant daily intake of honey in a range of 50 to $75 \mathrm{~g}$ wet weight can be achieved if SYHF is used in a meal replacement strategy; this amount may be sufficient to assume a significant intake of oligosaccharides and their related benefits forhealth and nutrition.

\section{Postprandial effects after SYHF intake}

To document an acute effect of a single intake of a defined SYHF bolus on energy supply and appetite regulation, two experimental studies have been performed with a controlled cross-over design in overweight males [45, 48].In the first study [45] eleven overweight male subjects with a diagnosis of metabolic syndrome and insulin resistance were investigated, following a randomized cross-overdesign, in the morning at fasting conditions; each subject consumed $65 \mathrm{~g}$ of the SYHF or an isoenergetic standardized breakfast; four hours after breakfast, all volunteers consumed a standardized lunch. Blood glucose, insulin, ghrelin, peptide YY (PYY) levels, oxygen uptake and carbon dioxide production were measured and the respiratory quotient and substrate supply for energy expenditure were calculated. A beneficial outcome of the SYHF breakfast was that the post-prandial glycemic and insulinemic responses were significantly lower compare to that following the standardized breakfast. In addition, in the obese insulinresistant subjects, the post-prandial decrease in fat oxidation was significantly less noticeable after the SYHF intake; this effect was also visible after lunch in terms of a second meal effect. Regarding the appetite regulation, ghrelin levels were significantly lower and PYY levels tended to be higher, 2 hours after the intake of SYHF breakfast. From these findings, it was concluded that compared to a typical carbohydrate rich breakfast a high protein and low glycemic SYHF intake was associated with lower glycemia and insulinemia as well as higher fat oxidation in the postprandial period. Take together with the favorable profile of appetite-regulating hormones, this may explain the benefit of a meal replacement SYHF strategy for weight reduction and the improvement of metabolic risk factors.
The results of the second study [48] confirmed the findings of a significant benefit of a SYHF rich breakfast. In this study, ten healthy male volunteers $(26 \pm 4.4$ yrs.; $23.2 \pm 0.9$ $\mathrm{kg} / \mathrm{m}^{2}$ ) were recruited to consume standardized isoenergetic breakfasts rich in either carbohydrate $68 \%$ of energy intake), fat ( $64 \%$ of energy intake) or protein $(35 \%$ of energy intake supplemented by SYHF) or a breakfast which reflected the individuals usual breakfast composition in a randomized design and controlled witha non-dietary day with onlyan intake of $200 \mathrm{ml}$ water.The state of satiety, blood glucose and lactate concentrations, resting oxygen uptake $\left(\mathrm{VO}_{\mathrm{Z}}\right)$ and respiratory quotient (RQ) were analyzed in a 4 hour postprandial period. Compared with the water control day, the most significant increases were found in blood glucose after the carbohydrate rich breakfast and the individual's usual breakfast, whereas the protein-rich SYHF supplemented breakfasts induced only small blood glucose responses; only after intake of the proteinrich SYHF, supplemented breakfast was there a significant increase in resting $\mathrm{VO}_{\mathrm{z}}$ (up to $30 \%$ ) without changes in RQ; in addition, the protein-rich breakfast induced the highest satiety feeling. According to the protein intake related effects, it was confirmed again that a SYHF supplemented breakfast may be of benefit for weight management and appetite regulation in adults. Furthermore, the results found after the intake of a single SYHF bolus may help to define the successful weight reduction using SYHF in a meal replacementstrategy.

\section{Successful weight reduction using SYHF}

It is now accepted that low-carbohydrate diets lead to a decreased energy intake and weightloss. However, it is unclear whether these effects are due to the reduced carbohydrate content of such diets or because of their associated increase in protein intake [5]. It has been confirmed in several studies that an increase in dietary protein at a constant carbohydrate intake produces a sustained decrease in ad libitum energy intake that may be mediated by increased central nervous system leptin sensitivity, resulting in significant weight loss $[27,68,84]$. It has also been confirmed in several studies that low fat diets, which reduce the fat content from $40 \%$ to $25-$ $30 \%$ of energy, also lead to weight loss [3].[84] showed that an increase in dietary protein from $15 \%$ to $30 \%$ of energy content and a reduction in fat from $35 \%$ to $20 \%$ at a constant carbohydrate intake, lead to a sustained decrease in ad libitum energy intake and significant weight loss. Moreover, diets with a fat content fixed at $30 \%$ of energy lead to more weight loss when higher in protein (25\%- $30 \%$ of energy) than when nearer to a usual protein level[3].

In the context of weight loss, the preservation of skeletal muscle mass is particularly important for the maintenance of motor competence and for the metabolic capacity of skeletal muscle [26]. A reduced fat and carbohydrate diet which is high in protein (particularly reflected in a SYHF diet), can lead to decreases in body weight and fat mass without any significant change in lean body mass[7].Several studies confirmed that the specific effect of SYHF on body 
composition could be observed in clinical trials after 6 and 24 weeks of meal replacement intervention[7, 27, 44, 47], when body composition was measured using air displacement plethysmography (Bod $\operatorname{Pod} \AA)$ [59].

In our 2008 published study [44], a total of 88 overweight and obese males and females $(47 \pm 7.5$ yrs., BMI $31.5 \pm 2.3 \mathrm{~kg} /$ $\mathrm{m}^{2}$ ) completed a 6 weeks intervention (29 participants in a lifestyle modification group (LSG), 59 subjects in a meal replacement group (MRG); in the LSG a fat-reduced diet (60\% of energy from carbohydrate, $25 \%$ from fat, $15 \%$ from protein; 1,200-1,500 kcal/day for women and 1,500-1,800 kcal/ day for men) was used. Participants assigned to the MRG were instructed to replace 2 daily meals with the prescribed low glycemic soy-yoghurt-honey formula [11]. The main findings from this study were, indicated that those following the meal replacement protocol, showed a greater improvement in body composition and significantly greater reductions in total body weight (BW), fat mass (FM) and especially waist circumference $(\mathrm{WC})(\mathrm{p}<0.01)$ compared with those in lifestyle group following an energy- restricted diet (diff. BW 6.4 vs. 3.1 $\mathrm{kg}$, diff. FM 5.1 vs. $2.8 \mathrm{~kg}$ ).

These findings correspond with the results of a metaanalysis of weight-loss trials, showing that very-low-calorie soy-based diets promote greater weight loss in a short period of time [2]. In the meal replacement group, the weight reduction was $1.8 \mathrm{x}$ higher than in the lifestyle group. This may have been because of a more effective dietary restriction in themeal-replacement strategies or a specific effect of the chosen dietary regimen. A well performed study [67] showed that a waist circumference reduction of $1 \mathrm{~cm}$ is equivalent to an abdominal fat loss of $0.33 \mathrm{~kg}$. Translating this factor, to our study, participants of the meal replacement group likely lost $1.8 \mathrm{~kg}$ of abdominal fat compared to a $0.5 \mathrm{~kg}$ loss in the lifestyle group. Considering the importance of abdominal fat in the pathogenesis of metabolic syndrome [79], it could be emphasized that the observed reduction in abdominal fat was an important factor in explaining the reduced prevalence of metabolic syndrome, even in short period of study time (see below).

Moreover, a study published recently [47] confirmed that a SYHF meal replacement strategy has the ability to lead to a significantreduction in bodyweight, total fat mass and internal abdominal fat while preserving lean body mass - comparable to an intensive lifestyle intervention program. The aim of that study was to focus on intervention induced changes in overweight subjects using Magnetic Resonance Imaging (MRI) for intra-abdominal fat stores measurements. The data from MRI analyses indicated that even with significant fat reduction in both groups, the abdominal fat loss in the LSG was due to a higher reduction in subcutaneous fat, whereas participants in the MRG lost more intra-abdominal/visceral fat/kg fat mass loss during the intervention. Finally, our results did not agree with the findings of a review [23] that the preferential loss of internal fat induced by low energy diets disappears when the intervention period extends to beyond four weeks.

In addition, there are data from elderly individuals, based on the effectiveness of SYHF meal replacement strategy, particularly in postmenopausal females [27]. In this study of 72 females, comparative clinical trial data (pre-menopausal: $\mathrm{n}=22,44 \pm 6.4$ yrs., $31.0 \pm 2.4 \mathrm{~kg} / \mathrm{m}^{2}$; postmenopausal: $\mathrm{n}=50$, $58 \pm 5.1$ yrs., $32.9 \pm 3.7 \mathrm{~kg} / \mathrm{m}^{2}$ ) showed that weight reduction was significant after 24 weeks when using a SYHF meal replacement together with a guided exercise program in both groups. When body composition was analyzed using Bod Pod ${ }^{\circledR}$ technology, the reduction of body weight was mainly due to a reduction in fat mass. Particularly in the postmenopausal women, the reduction of fat free mass (FFM) was $0.1 \mathrm{~kg}$, equal to only $1 \%$ of total weight loss. This finding is encouraging as it demonstrates that weight reduction using this type of intervention in postmenopausal women is feasible

Table 1: Results for body composition, metabolic and inflammatory status (mean \pm SD) in 2 subgroups before and after 24 weeks of intervention (controls vs. SYHF intake); p-values for pre-post intra-group paired differences were $p<0.05$ (a), p $<0.01$ (b), p<0.005 (c); p-values for the prepost inter-group unpaired differences were $\mathrm{p}<0.05(\mathrm{x}), \mathrm{p}<0.01(\mathrm{y}) . \quad[14,51]$

\begin{tabular}{|c|c|c|c|c|}
\hline & Control group (n=28)pre RCT & SYHF group (n=55)pre RCT & Control group (n=28)post RCT & SYHF group (n=55)post RCT \\
\hline BW(kg) & $91.2 \pm 11.6$ & $90.2 \pm 11.3$ & $84.9 \pm 10.8 \mathrm{c} / \mathrm{y}$ & $81.8 \pm 11.7 \mathrm{c} / \mathrm{y}$ \\
\hline FM(kg) & $36.9 \pm 6.27$ & $36.2 \pm 6.38$ & $30.4 \pm 7.60 \mathrm{c} / \mathrm{x}$ & $26.8 \pm 7.80 \mathrm{c} / \mathrm{x}$ \\
\hline Triglyc. $(\mathrm{mg} / \mathrm{dl})$ & $127 \pm 68.4$ & $143 \pm 66.0$ & $137 \pm 55.2$ & $133 \pm 71.9$ \\
\hline Apo B (mg/dl) & $115 \pm 20.3$ & $117 \pm 23.9$ & $105 \pm 20.9-/ \mathrm{x}$ & $97 \pm 21.6 \mathrm{c} / \mathrm{x}$ \\
\hline FBG(mg/dl) & $95 \pm 14.1$ & $95 \pm 12.2$ & $90 \pm 9.9 \mathrm{a}$ & $90 \pm 9.8 \mathrm{c}$ \\
\hline Insulin $(\mu \mathrm{m} / \mathrm{ml})$ & $8.8 \pm 3.92$ & $12.7 \pm 10.1$ & $7.4 \pm 3.98-/ \mathrm{y}$ & $7.1 \pm 5.02 \mathrm{c} / \mathrm{y}$ \\
\hline HOMA-Index $(\mathrm{U})$ & $2.2 \pm 1.26$ & $3.1 \pm 2.65$ & $28 \pm 20.7 \mathrm{~b} / \mathrm{y}$ & $1.6 \pm 1.17 \mathrm{c} / \mathrm{y}$ \\
\hline Leptin $(\mathrm{ng} / \mathrm{ml})$ & $37 \pm 29.2$ & $36 \pm 25.4$ & $1.8 \pm 2.30$ & $22 \pm 15.0 \mathrm{c} / \mathrm{y}$ \\
\hline IL-6(pg/ml) & $1.8 \pm 1.25$ & $2.2 \pm 2.05$ & $0.23 \pm 0.16$ & $1.7 \pm 1.29 \mathrm{a}$ \\
\hline hs-CRP $(\mathrm{mg} / \mathrm{dl})$ & $0.27 \pm 0.22$ & $0.30 \pm 0.28$ & $0.19 \pm 0.17 \mathrm{c}$ \\
\hline
\end{tabular}


without any significant reduction in lean tissue. In the context of weight loss, the preservation of skeletal muscle mass is particularly important for maintenance of motor competence and metabolic capacity, particularly in the elderly.

Finally, the SYHF concept and its benefits on body composition work also even if weight management is not the primary goal [29]. To determine these changes in body composition and physical performance induced by lifestyle counselling and resistance training together with soy proteinbased supplementation using SYHF product (50 g/d), 40 middle age males were investigated (50-65 yrs. BMI: 25-29.9 $\mathrm{kg} / \mathrm{m}^{2}$ ) in a randomized controlled study over a period of 12 weeks of intervention (resistance training with and without SYHF supplement vs. control group receiving only lifestyle education). Body composition, fat mass and fat-free mass (FFM) were measured by skin fold anthropometry at baseline and after 12 weeks of intervention. Despite significantchanges in bodyweight and sex hormones, FFM increased after training, particularly in participants who consumed SYHF supplement ( $\mathrm{n}=13$; FM: $22.6 \pm 5.5$ to $21.2 \pm 4.7 \mathrm{~kg}$; FFM: $68.5 \pm 7.2$ to $70.1 \pm 7.4$ kg; $<<0.01$ ); these participants also showed more noticeable improvements in strength measures than the participants who trained without the SYHF supplement. Therefore, it can be concluded that resistance training in combination with SYHF supplementation is more effective in adaptation to body composition as well as muscle mass and muscle function than lifestyle induced resistance training alone.

\section{Beneficial effects on metabolic dysfunction after SYHF meal replacement}

Considering the biological ingredients listed as potential metabolic activators of SYHF (see below), it is not surprising that a SYHF strategy, particularly as used as a meal replacement, shows significant benefits metabolic competence in overweight and obese adults (Tab.1). Furthermore, it can be assumed that the experimentally demonstrated changes in metabolic regulation are not only concomitant phenomena of the weight reduction process, but can also be explained by cellular and molecular activities of the ingredients themselves; in addition, it can be expected that these activities may complement one another and work synergistically. Because of the sum of these ingredients, the SYHF product shows promise as a formula for better health and against obesity associated comorbidities as documented in the following chapter.

As described in the first Almased review published in 2007 [9] the following metabolic changes have been confirmed in several recently published studies during the last years [14, $15,27,44,46,47,51]$; all indicated effects were substantiated in publically-registered and ethically approved controlled clinical trials. It can be confirmed that the SYHF application show sreproducible results including:

- a significant decrease in elevated fasting blood glucose and plasma insulinlevels -a significant improvement in HOMA index levels as an indicator for insulin sensitivity

-a significant decrease in serum LDL cholesterol and apolipoprotein B

- a significant decrease in serum triglycerides on increased baseline values

- a significant decrease of the plasma leptin levels

- a significant improvement in the inflammatory profile (hs-CRP, IL-6) at increased baseline values

When the leptin results were adjusted for age, gender, baseline leptin level, changes in body weight, and intervention type (lifestyle vs. SYHF meal replacement), the meal replacement approach had a clear independent effect on plasma leptin levels and enhanced the effects on leptin reduction resulting from weight loss [51]. Therefore, the findings suggest a relationship between SYHF intake and leptin regulation in the examined overweightadults(Tab.1).

It may be of additional interest that the metabolic improvements were accompanied by a significant reduction in blood pressure regulation [7, 27, 44], and that there is no indication that a SYHF rich diet affected kidney function negatively even in patients with the metabolic syndrome [30]. Together with the reduction in total body mass as well as body fat mass, lifestyle intervention with additional use of Almased $\AA$, promotes more favorable alterations in the metabolic status and regression in the systemically diagnosed symptoms of the metabolic syndrome. There is evidence that overweight patients showing symptoms of the metabolic syndrome benefit substantially from SYHF intervention, even when there was only an average weight reduction $[7,8,9,14,27$, 44]. This is also applicable for patients with prediabetes and those diagnosed with type 2 diabetes $[42,46]$.

\section{Beneficial effects of weight loss on quality of life and cognitive function after SYHF intake}

Obese individuals can experience social stigmatization and discrimination and severely obese people may experience greater risk of impaired psychosocial and physical functioning [43]. Indeed, a lower health-related quality of life (HRQOL) has been reported among obese people seeking intensive treatment for their condition. In addition, several studies have found an association between obesity and poor cognitive performance $[33,37,40]$ as well reduced quality of life $[20,21$, $31,38,55,56,72]$.

As previously mentioned, to aid the management of obesity, meal replacements have been recommended as an effective therapeutic strategy for weight loss, particularly when consumed at the beginning of an intervention. Hence, the objective of a trial conducted by the Freiburg study group [49] was to assess the impact of two 12-month weight reduction interventions (one arm including a meal replacement) on changes in HRQOL among obese women. This controlled trial compared two versions of a standardized 
12-month weight reduction intervention: the weightreductionlifestyle program without a meal replacement (LS) versus the same lifestyle program with the addition of SYHF meal replacement product (LSMR). 380 women (LS: $n=190$, LSMR: $\mathrm{n}=190$ ) were matched by age, gender and weight $\left(51.4 \pm 7.0\right.$ yrs., $\left.35.5 \pm 3.03 \mathrm{~kg} / \mathrm{m}^{2}\right)$. This sample of women all completed the 12-month lifestyle intervention that formed part of a larger study [10]. The lifestyle intervention included instruction on physical activity/exercise/sport, psychology, nutrition, and medicine in 18 theoretical and 40 practical sessions. Led by a sport physiologist, participants engaged in group-based exercise sessions once or twice a week. To evaluate HRQOL, all participants completed the SF-36 questionnaire pre- and post-intervention. Anthropometric, clinical, physical performance (ergometric stress tests), and self-reported leisure time physical activity (hours/day) data were collected. Health- related quality of life (HRQOL) was assessed by measuring bodily pain, general health perception and vitality $[39,77]$. The LSMR sample showed lower baseline HRQOL scores compared to the LS sample in six of eightHRQOL dimensions, most significant in vitality and health perception $(p<0.01)$. Post intervention, body weight was reduced in both groups (LS: $-6.6 \pm 6.6$ vs. LSMR: $-7.6 \pm 7.9 \mathrm{~kg}$ ). However, weight loss and HRQOL improvements were more pronounced in the LSMR sample (LSMR: seven of eight, LS: four of eight dimensions). The results showed that HRQOL may improve among middle-aged obese women during a standardized lifestyle weight reduction program and may be enhanced by consuming a soy-based meal replacement product.

Alternatively, several studies have found that soy isoflavones can also improve cognitive function in adults, but this effect may be inconsistent [53]. To determine potential benefits of soy food intake on cognitive function, our research group [18] investigated two samples of postmenopausal women, in a randomized double-blind trial; one group received isoflavone-rich SYHF and the other an isoflavone-free protein supplement. 68 clinically healthy postmenopausal women $\left(62.8 \pm 9.81 \mathrm{yrs}, 24.1 \pm 3.75 \mathrm{~kg} / \mathrm{m}^{2}\right)$ were randomized into a 10-weeks dietary intervention program accompanied with four cognitive tests of WTS Neuro (Fa. Schuhfried GmbH, Mödling, Austria: Cognitrone (COG), Linienverfolgungs test (LVT), Determinations test (DT), and California Verbal Learning Test (CVLT). Finding significant improvements in the COG and CVLT items for the SYHF group, we concluded that the daily intake of $50 \mathrm{~g}$ of the tested soy product induced a significant increase in blood isoflavone level with a positive influence on attention and concentration. Even if the improvement was at best $10 \%$, this improvement may be of clinical benefit in quality of daily life even in healthy elderly females. In conclusion, even if there is no general agreement about potential health benefits of soy food intake in older age groups, the results found in this placebo controlled study suggest that SYHF supplementation has a favorable effect on cognitive function, particularly attention and concentration, in postmenopausal women.

\section{Conclusion}

The results from all these studies relating to the SYHF formula of the commercially-available Almased $₫$ confirm that "The Almased concept" can be a successful approach to weight loss and to improve the metabolic milieu within a sustained time period, independent of sex, age and diagnosed symptoms of the metabolic syndrome. It has been demonstrated that even patients with metabolic dysregulation showed significant improvements and health benefits, after as little as six weeks of intervention. If this therapeutic approach is maintained, a weight reduction of more than $6 \mathrm{~kg}$ can be expected even in metabolically compromised patientsaftera shortperiodof time. Subsequent follow ups of the participants have confirmed that the initial rapid success in weight reduction is a motivating factor for further successful weight management. Therefore, increased attention should be given to this described meal replacement product. As a soy-yoghurt-honey combination, the formula (SYHF) showed not only an energy-sparing effect, but may also have potential health benefits beyond weight loss and in agreementwith the current literature. This impact may be driven by soy isoflavones as well as by specific soy and milk peptides, with honey ingredients also showing a variety of biological and molecular activities. Finally, the formula which was recommended in this review for weight management may play a feasible as well as safe principle in the achievement of therapeutic benefits in typical obesity- associated symptoms.

\section{Acknowledgment}

We would like to thank the Almased Wellness $\mathrm{GmbH}$ (Bienenbüttel, Germany) for their support in performing all of the cited studies related to SYHF.

\section{References}

1. Al-Waili N, Salom K, Al-Ghamdi A, Ansari MJ,Al-Waili A, Al-Waili T. Honey and cardiovascular risk factors, in normal individuals and in patients with diabetes mellitus or dyslipidemia. J Med Food. 2013;16(12):1063-1078. doi: 10.1089/jmf.2012.0285.

2. Anderson JW, Hoie LH. Weight loss and lipid changes with low-energy diets: comparator study of milk-based versus soybased liquid meal replacement interventions. J Am Coll Nutr. $2005 ; 24(3): 210-216$.

3. Astrup A, Grunwald GK, Melanson EL, Saris WHM, Hill JO. The role of low-fat diets in body weight control: a meta- analysis of ad libitum intervention studies. Int J Obes Relat Metab Disord. 2000;24(12):1545-1552

4. Astrup A, Rössner S. Lessons from obesity management programmes: greater initial weight loss improves long-term maintenance. Obes Rev. 2000;1:17-19.

5. Astrup Arne. The satiating power of protein: A key to obesity prevention? Am J Clin Nutr. 2005;82(1):1-2

6. Belitz HD, Grosch W. Textbook of Food Chemistry. 7th edition, Springer Verlag, Berlin Heidelberg NewYork, 2013.

7. Berg A, Frey I, Deibert P, Landmann U, König D, Schmidt-Trucksäss A, et al. Weight reduction is feasible. Half-year results from a clinically controlled, randomized intervention study with overweight adults. ErnährungsUmschau, 2003;50:386-393

8. Berg A, Frey I, Landmann U, Deibert P, König D, Berg A jr, et al. 
Weight reduction through lifestyle interventions: One-year results from a clinically controlled, randomized study of overweight adults. ErnährungsUmschau, 2005;52:310-314

9. Berg A, Landmann U. Clinical experience in the use of a calorie-reduced meal replacement. Adiposiras Spektrum. 2007; 6:20-24

10. Berg A, Berg A jr, Frey Ingrid, König Daniel, Predel HG. Exercise based lifestyle intervention in obese adults - Results of the intervention study M.O.B.I.L.I.S. Dtsch Arztebl 2008a;105(11):197203. doi: 10.3238/arztebl.2008.0197

11. Berg A, König D, Deibert P, Landmann U, Frey I, Kloock B, et al. Favorable metabolic properties of a soy- honey-yoghurt product for meal replacement in overweight subjects with atherogenic risk. Atherosclerosis 2008;9:253 DOI: 10.1016/S1567-5688(08)710158

12. Berg A, Schaffner D, Pohlmann Y, Baumstark MW, Deibert P, König D, et al. A soy-based supplement alters energy metabolism but not the exercise-induced stress response. Exerc Immunol Rev. 2012;18:128-141.

13. Berg A. Current results on the effect and effects of Almased $\AA$ as a meal replacement. 2012b, 13th anniversary of the Austrian Adiposity Society, Leibnitz Schloss Seggau, Austria.

14. Berg A. Influence of Almased on Body Composition and Metabolism: Details on Methods and Results of a Randomized, Controlled Intervention Study with Overweight Adults, 2013a. 14th anniversary of the Austrian Obedience Society, Leibnitz Schloss Seggau, Austria.

15. Berg A, Schaffner D, Stensitzky A, DeibertP, König D. A soy-yoghurthoney product improves body weight as well as metabolic milieu even after 6 weeks of intervention. J Diabetes. 2013b;5(s1):77.

16. Berg A, Koohkan S, Kempf K, Martin St, McCarthy D, Toplak H. The ALMASED Concept against Overweight and Obesity and Related Health Risk (ACOORH) has started. Diabetes Technology \& Therapeutics.2015;17(S1):A-140-141.

17.Berg A, Koohkan S, Banzer W, Braumann KM, Führer D, Halle M, Martin St, Predel G, Toplak H. The ALMASED Concept against Overweight and Obesity and Related Health Risk (ACOORH) - first results of an interims analysis. Diabetes Technology \& Therapeutics. 2016;18(S1):A-131-132

18. Berg A jr, Koohkan S, Deibert P, Schaffner D, König D, Bisse E, Berg A. Effects of isoflavon-rich soy-based supplement on cognitive function in postmenopausal women. 22nd Nordic Congress of Gerontology, Gothenburg, 2014.

19. Bogdanov S., Jurendic T, Sieber R, Gallmann P. Honey for Nutrition and Health: a Review. American Journal ofthe College of Nutrition. 2008;27(6):677-689

20. Brown WJ, Dobson AJ, Mishra G. What is a healthy weight for middle aged women?. Int J Obes Relat Metab Disord. 1998;22(6):520-527.

21. Brown WJ, Mishra G, Kenardy J, Dobson A: Relationships between body mass index and well-being in young Australian women. Int J Obes Relat Metab Disord. 2000;24(10):1360-1368.

22. Cassidy A. Potential tissue selectivity of dietary phytoestrogens and estrogens.Curr Opin Lipidol. 1999;10(1):47-52

23. Chaston TB, Dixon JB. Factors associated with percent change in visceral versus subcutaneous abdominal fat during weight loss: findings from a systematic review. Int J Obes (Lond). 2008;32(4):619-628. doi: 10.1038/sj.ijo.0803761

24.Crane, Eva. "The archaeology of beekeeping." London: Gerald
Duckworth \&Co. 1983.

25.Dansinger ML, Gleason JA, Griffith JL, Selker HP, Schaefer EJ. Comparison of the Atkins, Ornish, Weight Watchers, and Zone diets for weight loss and heart disease risk reduction: a randomized trial. JAMA 2005;293(1):43-53.

26.Deibert P, König D, Schmidt-Trucksäss A, Zaenker KS, Frey I, Landmann U, et al. Weight loss without losing muscle mass in preobese and obese subjects induced by a high-soy-protein diet. Int J Obes Relat Metab Disord 2004;28(10):1349-1352.

27.Deibert P, König D, Vitolins MZ, Landmann U, Frey I, Zahradnik $\mathrm{HP}$, et al. Effect of a weight loss intervention on anthropometric measures and metabolic risk factors in pre-versus postmenopausal women. Nutr J. 2007;6:31

28.Deibert P, König D, Kloock B, Groenefeld M, Berg A. Glycaemic and insulinaemic properties of some German honey varieties. Eur J Clin Nutr. 2010;64(7):762-764. doi: 10.1038/ejcn.2009.103.

29.Deibert P, Solleder F, König D, Vitolins MZ, Dickhuth $\mathrm{HH}$, Gollhofer A, et al. Soy protein based supplementation supports metabolic effects of resistance training in previously untrained middle aged males. Aging Male. 2011a;14(4):273-279. doi: 10.3109/13685538.2011.565091

30.Deibert P, Lutz L, Konig D, Zitta S, Meinitzer A, Vitolins MZ, et al. Acute effect of a soy protein-rich meal- replacement application on renal parameters in patients with the metabolic syndrome. Asia Pac J Clin Nutr. 2011b;20(4):527-534.

31.Doll HA, Petersen SE, Stewart-Brown SL. Obesity and physical and emotional well-being: associations between body mass index, chronic illness, and the physical and mental components of the SF36 questionnaire. Obes Res. 2000;8(2):160-170.

32.EFSA ANS Panel (EFSA Panel on Food Additives and Nutrient Sources added to Food).. Scientific opinion on the risk assessment for peri- and post-menopausal women taking food supplements containing isolated isoflavones. EFSA Journal. 2015;13(10):42461342

33. Elias MF, Elias PK, Sullivan LM, Wolf PA, D'Agostino RB. Lower cognitive function in the presence of obesity and hypertension: the Framingham heart study. Int J Obes Relat Metab Disord. $2003 ; 27(2): 260-268$.

34.Erejuwa 00, Sulaiman SA, Wahab MS. Oligosaccharides might contribute to the antidiabetic effect of honey: a review of the literature. Molecules. 2011;17(1):248-266. doi: 10.3390/ molecules17010248.

35.Erejuwa 00, Sulaiman SA, Wahab MS. Honey - A novel antidiabetic agent. Int J Biol Sci. 2012;8(6):913-934. doi: 10.7150/ijbs.3697

36. Erejuwa 00, Sulaiman SA, Ab Wahab MS. Honey: a novel antioxidant. Molecules. 2012;17(4):4400-4423. doi: 10.3390/ molecules17044400.

37.Farr SA, Yamada KA, Butterfield DA, Abdul HM, Xu L, Miller NE, et al.Obesity and hypertriglyceridemia produce cognitive impairment. Endocrinology. 2008;149(5):2628-2636. doi: 10.1210/en.20071722

38. Fine JT, Colditz GA, Coakley EH, Moseley G, Manson JE, Willett WC, et al. A prospective study of weight change and health-related quality of life in women. JAMA.1999;282(22):2136-2142. 
39. Fontaine KR, Bartlett SJ, Barofsky I. Health-related quality of life among obese persons seeking and not currently seeking treatment. Int J Eat Disord. 2000;27(1): 101-105

40.Jeong SK, Nam HS, Son MH, Son EJ, Cho KH. Interactive effect of obesity indexes on cognition. Dement Geriatr Cogn Disord. 2005;19(2-3):91-96.

41. Jones R. Honey and healing through the ages. In Munn P, Jones R (ed): "Honey and healing." Cardiff: International Bee Research Association IBRA. 2001:1-4

42.Kempf K, Schloot N, Gärtner B, Keil R, Schadewaldt P, Martin S. Proteinreiche Ersatzkost reduziert signifikant und langfristig den täglichen Insulinbedarf, den HbA1c und das Gewicht bei Patienten mit Typ 2 Diabetes mellitus, die mehr als >100 IE Insulin pro Tag benötigen. Diabetologie und Stoffwechsel. 2012;7:130

43. Khaodhiar L, McCowen KC, Blackburn GL. Obesity and its comorbid conditions. Clin Cornerstone. 1999;2(3):17-31.

44.König D, Deibert P, Frey I, Landmann U, Berg A. Effect of meal replacement on metabolic risk factors in overweight and obese subjects. Ann.Nutr.Metab 2008;52(1):74-8. doi: $10.1159 / 000119416$

45. König D, Muser K, Berg A, Deibert P. Fuel selection and appetiteregulating hormones after intake of a soy protein- based meal replacement. Nutrition. 2012;28(1):35-39. doi: 10.1016/j. nut.2011.02.008

46. König D, Kookhan S, Schaffner D, Deibert P, Berg A. A mealreplacement regimen improves blood glucose levels in prediabetic healthy subjects with impaired fasting glucose. Nutrition, 2014;30(11-12):1306-1309. DOI: 10.1016/j.nut.2014.03.014

47. König D, Zdzieblik D, Deibert P, Berg A, Gollhofer A, Büchert M. Internal Fat and Cardiometabolic Risk Factors Following a MealReplacement Regimen vs. Comprehensive Lifestyle Changes in Obese Subjects. Nutrients. 2015;7(12):9825-9833. doi: 10.3390/ nu7125500

48. Kritz-Silverstein, D, Von Mühlen D, Barrett-Connor E, Bressel MA Isoflavones and cognitive function in older women: the Soy and Postmenopausal Health In Aging (SOPHIA) Study. Menopause. 2003;10(3):196-202.

49. Koohkan S, Schaffner D, Milliron BJ, Frey I, König D, Deibert P, et al. The impact of a weight reduction programwith and without meal-replacement on health related quality of life in middleaged obese females. BMC women's health, 2014;14(1):45. doi: 10.1186/1472-6874-14-45.

50. Koohkan S, Baer M, Vitolins MZ,König D, Bisse E, Berg A. Influence of soy protein intake on blood isoflavone levels, thyroid and sex hormone concentrations in women, Poster presented at the American Women Healthcare \& Fitness Summit, 20.- 22.07.2015, San Francisco, USA

51. Koohkan S, Golesorkhi M, Vitolins MZ, H McCarthy DH, Deibert P, König D, Berg A. The influence of a meal replacement formula on leptin regulationin obese adults. J Hum Nutr Food Sci. 2016;4(4):15. DOI: $10.15226 /$ jnhfs. 2016.00169

52. Larson-Meyer DE, Willis KS, Willis LM, Austin KJ, Hart AM, Breton $A B$, et al. Effect of honey versus sucrose on appetite, appetiteregulating hormones, and postmeal thermogenesis. J Am Coll Nutr. 2010;29(5):482-493.

53. Lee YB, Lee HJ, Sohn HS. Soy isoflavones and cognitive function. J Nutr Biochem. 2005;16(11):641-649.
54.Lule VK, Garg S, Pophaly SD, Hitesh, Tomar SK. Potential health benefits of lunasin: a multifaceted soy-derived bioactive peptide. J Food Sci. 2015;80(3):R485-494. doi: 10.1111/1750-3841.12786

55.LePen C, Levy E, Loos F, Banzet M, Basdevant A: Specific scale compared with generic scale: a double measurement of the quality of life in a French community sample of obese subjects. J Epidemiol Commun Health. 1998;52(7):445-450. Doi: 10.1136/jech.52.7.445

56. Marchesini G, Bellini M, Natale S, Belsito C, Isacco S, Nuccitelli C, et al. Psychiatric distress and health-related quality of life in obesity. Diabetes Nutr Metab.2003;16(3):145-154

57.Martinez-Villaluenga C, Bringe NA, Berhow MA, Gonzalez de Mejia E. Beta- conglycinin embeds active peptides that inhibit lipid accumulation in 3T3-L1 adipocytes in vitro. J Agric Food Chem. 2008;56(22):10533-10543

58. Martínez I, Lattimer JM, Hubach KL, Case JA, Yang J, Weber CG, et al. Gut microbiome composition is linked to whole grain- induced immunological improvements. ISME J. 2013; 7(2):269-280. doi: 10.1038/ismej.2012.104.

59. McCrory MA, Gomez TD, Bernauer EM, Mole PA: Evaluation of a new air displacement plethysmograph for measuring human body composition. Med. Sci. Sports Exerc. 1995;27(12):1686-1691.

60.Messina MJ. Legumes and soybeans: overview of their nutritional profiles and health effects. Am J Clin Nutr 1999;70(3 Suppl):439-449

61. Mezei O, Banz WJ, Steger RW, Peluso MR, Winters TA, Shay N. Soy isoflavones exert antidiabetic and hypolipidemic effects through the PPAR pathways in obese Zucker rats and murine RAW 264.7 cells. J Nutr. 2003;133:1238-1243

62.Morifuji M, Sanbongi C, Sugiura K. Dietary soya protein intake and exercise training have an additive effect on skeletal muscle fatty acid oxidation enzyme activities and mRNA levels in rats. Br J Nutr. 2006;96(3):469-475

63.Moriyama T, Kishimoto K, Nagai K, Urade R, Ogawa T, Utsumi S, et al. Soybean beta-conglycinin diet suppresses serum triglyceride levels in normal and genetically obese mice by induction of beta-oxidation, downregulation of fatty acid synthase, and inhibition of triglyceride absorption. Biosci Biotechnol Biochem. 2004;68(2):352-359.

64. Nemoseck TM, Carmody EG, Furchner- Evanson A, Gleason M, Li A, Potter $\mathrm{H}$, et al. Honey promotes lower weight gain, adiposity, and triglycerides than sucrose in rats. Nutr Res. 2011;31(1):55-60. doi: 10.1016/j.nutres.2010.11.002.

65.North American Menopause Society. The role of soy isoflavones in menopausal health: report of The North American Menopause Society/Wulf H. Utian Translational Science Symposium in Chicago, IL (October 2010). Menopause. 2011l;18(7):732753. doi: $10.1097 / \mathrm{gme} .0 \mathrm{~b} 013 \mathrm{e} 31821 \mathrm{fc} 8 \mathrm{e} 0$.

66.Padwal RS, Majumdar SR. Drug treatments for obesity: orlistat, sibutramine, and rimonabant. Lancet. 2007;369(9555):71-77.

67.Ross R, Dagnone D, Jones PJ, Smith H, Paddags A, Hudson R, et al. Reduction in obesity and related comorbid conditions after diet-induced weight loss or exercise-induced weight loss in men. A randomized, controlled trial. Ann Intern Med. 2000;133(2):92103.

68.Rolls BJ, Hetherington M, Burley VJ. The specificity of satiety: the influence of foods of different macronutrient content on the development of satiety. Physiol Behav. 1988;43(2):145-153. 
69. Ronis MJ, Chen Y, Badeaux J, Badger TM. Dietary soy protein isolate attenuates metabolic syndrome in rats via effects on PPAR, LXR, and SREBP signaling. J Nutr. 2009;139(8):1431-1438. doi: 10.3945/jn.109.107029

70.Setchell KD, Cassidy A. Dietary isoflavones: biological effects and relevance to human health. J Nutr. 1999;129:758S-767S.

71.Singh BP, Vij S, Hati S. Functional significance of bioactive peptides derived from soybean. Peptides. 2014;54:171-179. doi: 10.1016/j. peptides.2014.01.022

72.Sullivan M, Karlsson J, Sjöström L, Taft C. Why quality of life measures should be used in the treatment of patients with obesity. International Textbook of Obesity. Edited by: Björntorp P. 2001. New York: John Wiley \& Sons,485-510. DOI: 10.1002/0470846739. $\operatorname{ch} 33$

73.Summerbell CD, Watts C, Higgins JP, Garrow JS. Randomised controlled trial of novel, simple, and well supervised weight reducing diets in outpatients. BMJ. 1998;317(7171):1487-1489

74.Torres N, Torre-Villalvazo I, Tovar AR. Regulation of lipid metabolism by soy protein and its implication in diseases mediated by lipid disorders. J Nutr Biochem. 2006;17(6):365-373

75. Udenigwe CC, Aluko RE. Food Protein-Derived Bioactive Peptides: Production, Processing, and Potential Health Benefits. Journal of food science. 2012;77(1):11-24. doi: 10.1111/j.1750-3841.2011.02455.x

76. Velasquez MT, Bhathena SJ. Role of dietary soy protein in obesity. Int J Med Sci. 2007;4(2):72-82.

77. Wadden TA, Phelan S. Assessment of quality of life in obese individuals. Obes Res. 2002;10(Suppl 1):50S-57S.

78. Wagner JD, Zhang L, Shadoan MK, Kavanagh K, Chen H, Tresnasari $\mathrm{K}$, et al. Effects of soy protein and isoflavones on insulin resistance and adiponectin in male monkeys. Metabolism. 2008;57(7 Suppl 1):S24-31. doi: 10.1016/j.metabol.2008.04.001.

79.Wajchenberg BL. Subcutaneous and visceral adipose tissue: their relation to the metabolic syndrome. Endocr Rev. 2000;21(6):697738.

80.Walsh CJ, Guinane CM, O’Toole PW, Cotter PD. Beneficial modulation of the gut microbiota. FEBS Lett. 2014;588(22):41204130. doi: 10.1016/j.febslet.2014.03.035

81.Wasielewski H, Alcock J, Aktipis A. Resource conflict and cooperation between human host and gut microbiota: implications for nutrition and health. Ann NY Acad Sci. 2016;1372(1):2028. doi: 10.1111/nyas.13118.

82.Watanabe S, Yamaguchi M, Sobue T, Takahashi T, Miura T, Arai Y, et al. Pharmacokinetics of soybean isoflavones in plasma, urine and feces of men after ingestion of $60 \mathrm{~g}$ baked soybean powder (kinako). J Nutr. 1998;128(10):1710-1715.

83. Wechsler JG, Wenzel H, Swobodnik W, Ditschuneit H. Modified fasting in the therapy of obesity. A comparison of total fasting and low-calorie diets of various protein contents. Fortschr Med. 1984;102(24):666-668.

84.Weigle DS, Breen PA., Matthys CC, Callahan HS, Meeuws KE, Burden VR, et al. A high-protein diet induces sustained reductions in appetite, ad libitum caloric intake, and body weight despite compensatory changes in diurnal plasma leptin and ghrelin concentrations. Am J Clin Nutr. 2005;82(1):41-48.

85.Wirth A, Wabitsch M, Hauner H. The prevention and treatment of obesity. Dtsch Arztebl Int. 2014;111(42):705-713. doi: 10.3238/ arztebl.2014.0705.

86.Zaloga GP, Siddiqui RA. Biologically active dietary peptides. Mini Rev Med Chem. 2004;4(8):815-821. 